\title{
The nature of Formal Reasoning among Ghanaian Basic School pupils in General Science Logic Tasks
}

\author{
Amedeker, M. K. \& Abdul-Rahman, L. \\ University of Education, Department of Science Education, Winneba. Ghana
}

\begin{abstract}
Many Psychologists have considered early formal thinking among adolescents as signs of normal development. As it is not known for certain at what age Ghanaian Junior Secondary School (JSS) pupils achieve formal operational capabilities, the study seeks to find out the relationship between Piagetian theory of development and the extent of formal thinking among adolescent pupils, especially in General Science Logic tasks. This study thus used two sets of questionnaire involving "General Knowledge Logic Tasks" and "General Science Logic Tasks" based on topics chosen from the JSS science syllabus to test the logical reasoning of pupils between ages of 13 and 15 years. A total of 60 pupils were selected randomly from four junior secondary schools and tested on the questionnaire. The sample was made up of 15 pupils (with 5 from each of JSS 1 to JSS 3) from each school. They were then served with the same items. The marks they obtained on the two examinations were used to determine the extent of their formal reasoning as well as their maturity. It was found, rather surprisingly, that the older pupils did less formal reasoning than the younger ones. That is, the younger pupils in JSS 1 (age 13-14 years) performed better on the tests than those in JSS 2 (ages 14-15 years) and JSS 3 (ages 15-16 years). It was also found that on the average all pupils performed better on the General Knowledge tasks than on the General Science tasks, implying that pupils' formal reasoning was not subject oriented. This anomaly may be attributed to the fact that many pupils resort to rote learning and as a result forget soon afterward what they had learned while their knowledge of happenings around them lasted longer.
\end{abstract}

\section{Introduction}

Shayer and Adey (1993) have noted that pupils should be able to develop early science formal thinking in Piagetian terms as early as at age 9 years. This they attributed to the fact that secondary school science and mathematics courses require formal operational thinking. It is only such early development that would enable students to grasp the full import of the current over-demanding senior secondary school science syllabus. The science syllabuses in both junior and senior secondary schools require that learners develop new thinking skills in the learning context in which they are involved.

Case (1992) in alluding to Piagetian theory agrees that there exist domainindependent internal operations in any child. These coherent internal operations are supposed to evolve and transform the cognitive developmental changes of the child. Piagetian theory therefore falls under what may be termed as contextual-neutral theories of cognitive development. These theories have, however, been criticized by many developmental theorists. For example, Bidell and Fischer (1992) debased the extensive reliance on the cognitive approach to education and wondered if it ever made any widespread success. The reason for this doubt is that there still existed a wide gap between developmental theory and educational practice. Thomas et al. (1992) also argued that there existed an apparent contradiction for educators who wanted to use traditional educational theories as tools for analysing specific 
educational processes. This assertion is based on the assumption that context-neutral theories of cognitive development separated the organization of knowledge from practice. They disputed that organization of thought and knowledge ever was primarily a property of a person. Their reason was based on the fact that specific interventions are known to have brought about contextual variation of the organization of thought and knowledge. Norman (1997) described the theory of decontextualized reasoning as archaic. He claims that content and context were crucial in determining human reasoning. However, the several arguments against context-neutral theories of cognitive development have not been replaced by alternative theories. In fact no theoretical bases have been formulated for incorporating the effect of content into reasoning. Thus content-independent developmental theories have remained the basis for interpreting and assessing human reasoning. Content has been viewed as a factor that could either facilitate or hinder logical reasoning.

Norman (1997) describes Lawson's theory of multiple hypotheses as one that comprises reasoning with more than one antecedent condition. These conditions may be classified as a scheme of immediate consequence and a scheme of activation. In terms of academic knowledge, a scheme may be considered as thought processes involved in reasoning to give an answer to a question. Thus the one with more schemes (i.e. thought processes) is said to have more formal reasoning.

The study thus tries to find out if JSS pupils in Ghana do use several thought processes in answering questions in general science and in general knowledge tasks. The sample consisted of 60 pupils from JSS1 - JSS3 chosen from four schools in the Winneba township.

\section{The Piagetian Theory}

Piaget's theory prescribes three descriptions for formal reasoning patterns which form a schemata:

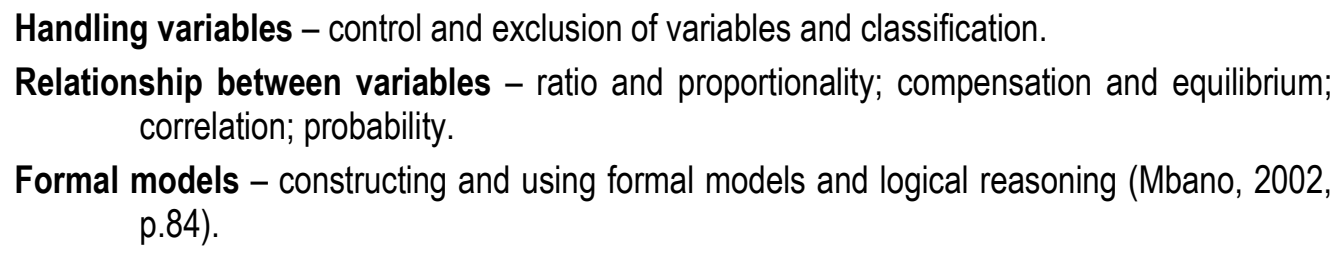
correlation; probability.

Formal models - constructing and using formal models and logical reasoning (Mbano, 2002, p.84).

The achievement of formal operational thinking is developmental. In this study it is a response to thinking about variables, and their values and relationships. The central idea here is to think about thinking - a process described by Mbano (2002) as metacognition.

The developmental process expects pupils who have attained the formal reasoning age to become independent thinkers who can analyze complex problems and also apply what they have learnt to real-life situations. Thomas and Emereole (2002) feel that all the knowledge and skills needed in life cannot be acquired in school. Thus one has to be a life-long learner in order to succeed in a rapidly changing world. Indeed modern technologies such as the Internet, mobile-networked technologies and the computer have been known to have improved the quality of teaching and learning (Chan and 
Wang cited in Thomas and Emereole, 2002). Other authors (Papert, 1993; Ward, 1994; Fletcher -Flinn and Gravatt, 1995; Poole, 1997; Ruffini, 1999) have reported positive impact of the modern technologies on students' achievement. Despite the glories of the modern technologies the maturity of the learner cannot be overlooked. This needs to happen in relation to pedagogic and contextual knowledge. This is the more reason why the attainment of formal reasoning at the appropriate age is of concern in this work.

\section{Objectives}

The question that guided the study was: "What is the nature of formal reasoning among Ghanaian Junior Secondary School pupils (ages 13 - 16 years)? Normally pupils in JSS1-JSS3 are in the age ranges of 13 to 16 years but in the sample some few pupils were found to be up to 19 years. To address the question, the researchers:

(1) Administered logic tests in general knowledge to pupils in J.S.S 1 - JSS 3.

(2) Administered logic tests in general science to pupils in J.S.S.1-JSS 3.

(3) Made a comparative analysis of pupils' achievements on the two types of tests.

The assumption underlying this study was that as pupils advance to higher educational levels they move away gradually from concrete operational stage to the formal reasoning stage. It is, therefore, expected that JSS 3 pupils would perform better on the logic tests than JSS 2 and JSS 1 pupils. Also the JSS 2 pupils are expected to perform better than JSS 1 pupils on the tests. The tests were designed to find general cognitive development as well as cognitive development in science. The topics chosen for the general science test were from the JSS 1 General Science syllabus (CRDD, 2000). In the junior secondary schools, students receive four hours of General Science instruction per week. Though there are no laboratory practices, teachers are expected to teach with activities and demonstrations using materials obtained from their immediate environment. Thus teachers are encouraged to create science corners so as to store materials gathered for teaching and learning. Teacher preparations programme dubbed improvisation techniques is one of the courses taught in the teacher training colleges. In this programme teacher-trainees are taught to construct teaching and learning materials from objects they collect from their localities. The constructivists' approach to teaching is encouraged by the J.S.S. science syllabus. This is an approach that advocates the acquisition of knowledge by exploring one's own mental models and alternative concepts. On the other hand teacher-oriented approach to teaching is not encouraged. This in line with the findings of Ritchie, Tobin and Hook (1997) that excessive exposure referent or teacher dominated lessons (authoritarian approach) cowed students into acquiring knowledge without exploring their own mental models. Thus it may be argued that authoritarian approach to science teaching may also not allow learners to develop formal reasoning even at ages outside the Piagetian concrete operational stage.

\section{Methodology}

There were five items on each of the General Logic Tasks (GLT) and the General Science Logic Tasks (GSLT). These are shown in Appendix 1. The items on the GSLT were based on topics chosen from the JSS 1 Integrated Science Syllabus. This 
was done with the anticipation that the senior classes (JSS 2 and JSS 3) had learnt these topics already and that the JSS 1 pupils had also just completed the topics. Each task had three options from which pupils were to choose the one they considered the most appropriate. The options represented conclusions that could be drawn from two premises stated earlier. Only one option could be correct for an answer. For example the first task on the GLT (shown in Appendix 1) had the following two premises followed by some conclusions:

GLT task 1:

- If the school flag is flying then the national anthem was sung in the morning;

- The school flag is not flying; therefore,

A. the national anthem might have been sung in the morning.

B. the national anthem was not sang in the morning.

C. no conclusion can be drawn.

The respondents were then required to draw a conclusion from the two premises and this was to be chosen from the three options given below the premises (lettered A C). In this instance one has to make use of alternate conditions in the context of the problem in order to find the solution to the problem. There is a condition (factor) and its effect. The factor is singing the national anthem and the effect is that the school flag will be hoisted so it will be seen flying. This condition and the effect show that the two activities go together. One must then identify the antecedent of the problem. Clearly the antecedent is that the national anthem is sung first and then after that the school flag is hoisted so it is seen flying. Thus the alternate condition (the effect) cannot occur when the first condition has not occurred. The conclusion to the above item then is that since the first condition has not occurred (that is the national anthem has not been sung) then the second condition cannot occur (the school flag will not be flying). Thus the correct option for the first item above is alternative " $\mathrm{B}$ ".

In GLT task 2, the condition is buying a ticket at the stadium gate and the effect is that you are allowed into the stadium. Here there is a condition that might affect the situation (alternate condition) and that is Kwesi might have bought the ticket for someone. Thus Kwesi may not enter the stadium. The appropriate option then is $\mathrm{C}$ that is "no conclusion can be drawn".

Similarly in GLT task 3, the alternate condition affects the first condition. A goal may be disallowed despite the fact that the ball has entered the goal. This disqualification may be due to an infringement of one of the rules of the game. Thus the correct option then is $\mathrm{C}$ - that is "no conclusion can be drawn."

In GLT task 4, the condition is that it does not rain and the effect is that we will go out to play. Since no alternate condition exists in the context to affect the situation, then the subsequent action is that we will go out to the field to play. Option A is then the correct answer.

In GLT task 5 the first condition is the fact that Kofi's interest in girls makes him to be in the company of girls. The alternate or the interfering condition within the context of the task is that another boy, other than Kofi, who is also interested in girls may join the company of the girls. Thus the boy found in the company of the girls 
may or may not be Kofi. Thus no conclusion can be drawn so option $\mathrm{C}$ is the correct answer.

We now analyse the GSLT tasks (Appendix 1). The first task had the following two premises followed by some conclusions:

GLST task 1:

- "Work done is defined as the amount of energy exerted by a person pushing a load over a distance"

- "Ama pushed her Dad's car when it would not start"
A. she did work.
B. she did not do work.
C. no conclusion can be drawn.

The condition (factor) here is the exertion of energy to push a load over a distance. The effect is that work is done. The alternate condition is that energy may be exerted but the load may not be moved over a distance. The effect of the alternate condition is that no work is done. It is, however, not known whether Ama was able to push the car for it to move over some distance. Thus no conclusion can be drawn (option C).

In GSLT task 2, the condition is that all organisms are living things. There is an inherent interfering condition that living things may be plants or animals. Thus specimen $\mathrm{X}$ needs to be classified before a conclusion can be drawn. Option C - "no conclusion can be drawn" is the correct option.

In GSLT task 3 the first condition requires that one recognises the components of carbon monoxide as oxygen and carbon. However, it is not the only gas made up of solely oxygen and carbon. Since carbon dioxide is also made up of solely carbon and oxygen atoms then no conclusion can be drawn about the gas in the jar so option $\mathrm{C}$ is correct.

The GSLT task 4 also had two conditions that respondents had to use to draw a conclusion about the task. Respondents were to recognize that lungs were essential for respiration but there were some animals that did not respire through lungs. The statement that lungs were important for respiraton did not preclude the fact that respiration could occur without lungs. As the animal was moving about in the bottle then it was living and subsequently must respire. Respiration is a characteristic of living things. Thus an animal without lungs could use other means of respiration. It would thus not be expedient to conclude that once an animal did not possess lungs then it does not respire. In the circumstances the most appropriate conclusion is that the animal does not respire through lungs - option B.

The last task, GSLT task 5, also had two main conditions - that is the effect of heat on metals and the various consequences of this effect. One has to know that expansion can take various forms - it could go in linear direction or otherwise. Thus one cannot conclude that in expansion the metal must coil around an object. This is because there is no condition in the premise that implies that the metal has been positioned as to coil around an object. The only conclusion that be drawn is that since the metal has been heated so it would increase in volume - option B. 
In scoring the tasks each correct option was awarded 1 mark. Thus the GLT and GSLT were each scored over a total of 5 marks. The marks for the four schools that participated were then pooled together and the mean scores on each of GLT and GSLT was determined for the three classes (Table 1). It was not necessary to find the mean for the performance of each school as the research was meant to determine a global performance of each JSS class. Thus the mean performances were calculated for all of JSS 1, JSS 2 and JSS 3 classes involved in the research. Mean plots were then made for the three classes (fig 1a) and the various ages in the sample (fig 1b) by using a computer-based mathematical software known as Statistical Package for the Social Sciences (SPSS). These graphs showed the mean performances in the GLT and the GSLT for the classes and the various ages present in the sample.

\section{Results and Discussion}

The findings show that subjects of the research differed greatly in their responses to the tasks. The choices they presented for the alternatives varied very much (the correct answers are shown with asterisks in Appendix 1). The results show that when it comes to reasoning, there is no context-neutral construct as is portrayed by Piagetian theory. A cursory look at the mean scores obtained by the various classes (Table 1) shows that the JSS 3 group had the least averages in both GLT and GSLT tasks. This is rather surprising and disappointing, as one would expect the contrary. It appears that the JSS 3 group suffered diminished memory retention - skills, concepts and strategies had diminished.

Table 1 Average performance of pupils on the GLT and GSLT tasks

\begin{tabular}{llll}
\hline \multirow{2}{*}{ Tasks } & \multicolumn{2}{c}{ Means } \\
\cline { 2 - 4 } & JSS 1 & JSS 2 & JSS 3 \\
General Logic Tasks (GLT) & & & \\
General Science Logic Tasks (GSLT) & 2.40 & 2.30 & 2.15 \\
\hline
\end{tabular}

Mbano (2002) reported a similar work in which a large representative sample of adolescents in Britain showed that only about $28 \%$ of 14 year olds were at the early formal operational stage. It was found that most secondary school curricula required formal operational thinking for comprehension. Since our results (Fig. 1) appear to show that our pupils who will go on to the senior secondary schools are not retaining what they learn then we could ask if these pupils can learn senior secondary school science at all. 


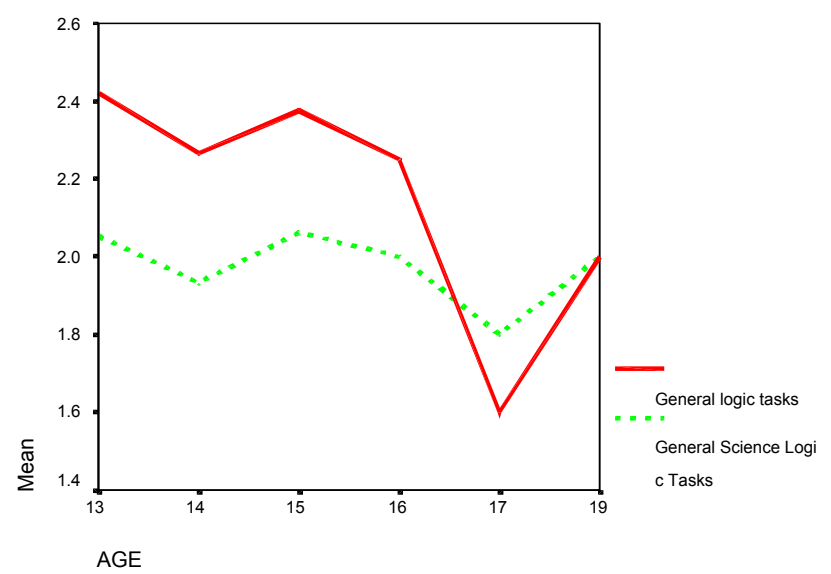

Fig. 1(a). Mean performances for the age groups

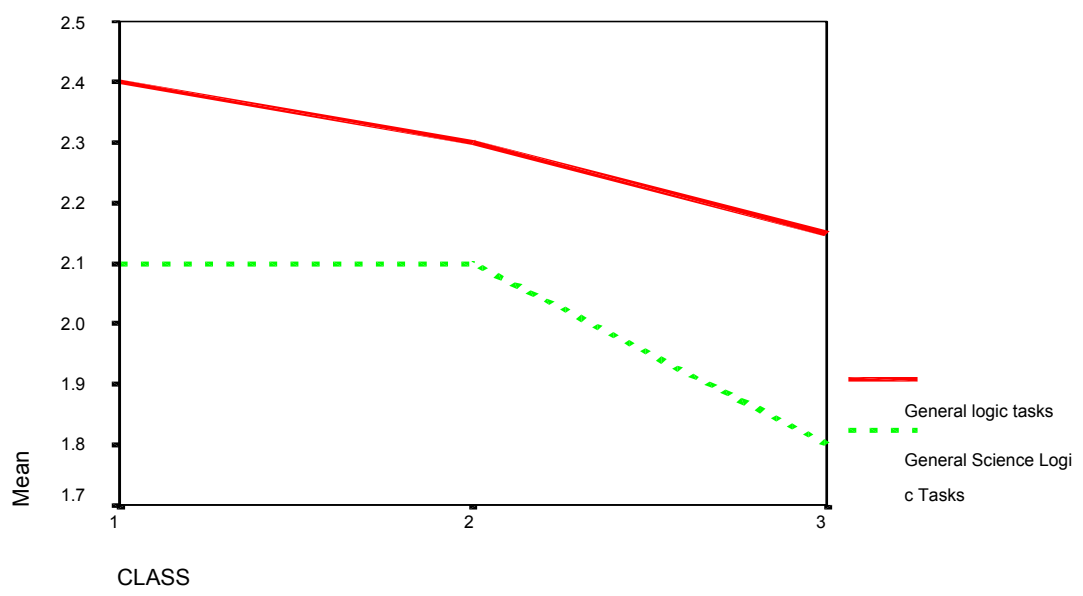

Fig. 1(b). Mean performances for the classes (JSS 1 to JSS 3)

The results show that many of the subjects were operating at the pre-formal operational stage because they could not recognize the alternate conditions in the context of the tasks. Thus such subjects used conditional logic only. The conditional pattern of reasoning does not take care of other existing conditions that might affect the conclusions that could be drawn. The task on the composition of gases (GLST 3) was the least appropriately answered. The reason may be that pupils had insufficient knowledge of the nature of matter.

The problems associated with teaching and learning cannot be blamed on only one group of stakeholders in education. Teachers as stakeholders in education have a vital role to play in teaching for retention. In Ghana however, it appears that most teachers, particularly at the basic education level, do not use the constructivists' approach to teaching. A constructivist approach to the teaching and learning process is one that expects learners to acquire essential credible knowledge and not a set of truths (Ritchie, Tobin and Hook, 1997). These authors identified three main warrants - authority, coherence and empirical evidence - as methods of acquiring credible knowledge. They found, however, that excessive content exposure referent or teacher dominated lessons (i.e. the authority approach) cowed students into acquiring knowledge without exploring their own mental models and alternative concepts. Thus 
students who are always exposed to authority-dominated approach to teaching may not develop formal reasoning even at ages outside the concrete operational stage. This is what appears to have happened to the subjects of this study. Their formal reasoning appears to assume a declining trend as they advance in age and also progress to higher classes. As pupils move from a lower educational stage to the higher stage they appear to forget what they had learnt earlier. Their formal reasoning assumes a declining nature.

The above findings are in line with the assertion of Bidell and Fischer (1992) that despite the promising nature of cognitive development theories, attempts to apply them did not meet widespread success. The failure, they attributed to a sizeable gap between developmental theory and educational practice. In Ghana, for example, the most qualified and experienced teachers are put in the senior secondary schools while the least qualified ones are put in the basic schools (i.e. primary schools and junior secondary schools). Thus teaching and learning at the basic schools are fraught with problems such as ineffective teaching and rather slow cognitive developmental changes. Many teachers in the basic schools have not benefited from in-service training for many years. They are thus glued to methodologies which when faulty remain so all the time with the attendant lack of exposure to improve their educational practices. These are teachers whose knowledge in science is even questionable, as they might not have done science to any great depth.

\section{Conclusion and Implications}

Formal operators must be able to distinguish between false and logical arguments. This is because they must be able to analyse, reconstruct or restructure the problem situation in order to generate workable hypotheses. Initiating reasoning with more than one antecedent (premise) is characteristic of formal reasoning thus concrete operational pupils will not be able to differentiate between the "probable" and the "possible". Thus concrete operational pupils cannot generate appropriate alternate conditions. On the other hand the JSS science syllabus exacts deep-seated understanding of scientific principles and laws. This means that changes in methodologies of presenting science concepts are needed for a change for the better in our junior secondary school science teaching and learning. van Driel, Beijaard and Verloop (2001) have found, from a series of research report reviews, that sufficient time, resources and continuous professional development programmes are essential for ingraining in teachers practices that are consistent with the constructivists, approach to teaching. Since thinking about how variables affect one another in a given context is relevant to hypothesis generation, methods of teaching should be geared towards enriching learners with the skills of critical thinking to enable them analyse situations.

This study recommends similar studies with larger samples to determine whether the trend observed in this work is typical of Ghanaian pupils.

\section{References}

Bidell, T. R. and Fischer, K. W. (1992) Cognitive Development In Demetriou, A. Shayer, M. and Efkilides, A. (Eds). Educational contexts: Neo-Piagetian 
theories of Cognitive development. Routledge, Chapman and Hall Inc., pp 1130 .

Case, R. (1992) The role of conceptual structures in the development children's scienctific and mathematical thought. In Demetriou, A. Shayer, M. and Efkilides, A. (Eds). Educational contexts: Neo-Piagetian theories of Cognitive development. Routledge, Chapman and Hall Inc pp. 52-64.

Curriculum Research and Development Division - CRDD - (2000). Integrated Science Syllabus for Junior Secondary School: Book 1. Accra: Ghana Education Service.

Fletcher-Flinn, C. M. and Gravatt, B. (1995) The efficacy of computer-assisted instruction (CAI); A meta-analysis. Journal of Educational Computing Research, 12, pp. 219-241.

Mbano, N. (2002) Verbal interactions in CASE lessons in Malawi. African Journal of Research in Mathematics, Science and Technology Education, 6, pp. 83-94.

Norman, O. (1997) Investigating the nature of formal reasoning in Chemistry: Testing Lawson's Multiple hypothesis Theory. Journal of Research In Science Teaching. 34 (10), pp. $1067-1081$.

Papert, S. (1993) The Children's Machine: Rethinking School in the Age of the Computer. New York: Basic books Inc.

Poole, B. (1997) Education for an Information age. Boston: WCB McGraw-Hill.

Ritchie, S. M., Tobin, K. and Hook, K. S. (1997) Teaching Referents and the Warrants used to test the Validity of Students' Mental Models: Is there a Link? Journal of Research In Science Teaching. 34 (3), pp. 223 - 238.

Ruffini, M. F. (1999) The impact of undergraduate pre-service teachers' use of hypermedia to review lecture notes. Journal of Research on Computing in Education, 31, pp. 292-304.

Shayer, M. and Adey, P. (1993) Accelerating the development of formal reasoning , Journal of Research In Science Teaching. 30 (4), pp. 351-365.

Thomas, P. Y. and Emereole, H. U. (2002) Effect of computer-based instruction on performance in physics. African journal of Research in Mathematics, Science and Technology Education, 6, pp 97-112.

Thomas, R. et al., (1992) Neo-Piagetian Theories of Cognitive development. In Demetriou, A. Shayer, M. and Efkilides, A. (Eds). Educational contexts: NeoPiagetian theories of Cognitive development. Routledge, Chapman and Hall Inc, pp. 65-80

van Driel, J. H., Beijaard, D. and Verloop, N. (2001) Professional development and reform in science education: The role of teachers' practical knowledge. Journal of Research in Science Teaching, 38, pp. 137 - 158

Ward, A. W. (1994) Multimedia and learning: A school leader's guide. Alexandria, VA : National School Boards Association. 


\section{Appendix 1}

\section{GENERAL LOGIC TASKS}

TASK 1:

- If the school flag is flying then the national anthem was sang in the morning.

- The school flag is not flying, therefore

Task 2:
A. the national anthem might have been sung in the morning.
B. the national anthem was not sang in the morning.*
C. no conclusion can be drawn.

- You are allowed into the stadium if you buy a ticket at the gate.

- Kwesi bought a ticket at the gate, therefore
A. Kwesi is in the stadium.
B. Kwesi is not in the stadium.
C. no conclusion can be drawn.*

Task 3:

- In soccer if the football is shot into the net then a goal is scored.

- A goal has not been scored, therefore
A. the football has not been shot into the net.
B. the football has been shot into the net.
C. no conclusion can be drawn.*

Task 4:

- If it does not rain during break, we play on the field.

- It will not rain during break, therefore
A. we will play on the field.*
B. we will sit in the classroom.
C. no conclusion can be drawn.

Task 5:

- Kofi likes the company of girls.

- There is a boy standing over there with the girls, therefore
A. the boy is Kofi.
B. the boy is not Kofi.
C. no conclusion can be drawn.*

Note: The correct options have been marked with asterisks 


\section{General Science Logic Tasks}

Task 1:

- Work done is defined as the amount of energy exerted by a person pushing a load over a distance.

- Ama pushed her Dad's car when it would not start, therefore
A. she did work.
B. she did not do work.
C. no conclusion can be drawn.*

Task 2:

- All organisms are living things.

- The specimen labeled $\mathrm{X}$ is an organism, therefore
A. it is an animal.
B. it is a plant.
C. no conclusion can be drawn.*

Task 3:

- Carbon monoxide is made up of only carbon and oxygen.

- The gas in this jar is made up of only carbon and oxygen, therefore
A. the gas is carbon monxide.
B. the gas is carbon dioxide.
C. no conclusion can be drawn.*

Task 4:

- Lungs are important organs for respiration.

- The animal moving in the bottle has no lungs, therefore
A. it does not respire.
B. it does not respire through lungs.*
C. no conclusion can be drawn.

Task 5:

- Metals generally expand when heated.

- The effect of heat on metals, therefore, is to
A. make them coil around another material.
B. Increase their volume.*
C. No conclusion can be drawn.

Note: The correct options have been marked with asterisks 